\title{
UM OLHAR SOBRE A TRADIÇÃO E O MODERNO NAS ORQUESTRAS DE VIOLEIROS
}

\section{AN OVERVIEU OF THE TRADITION AND THE MODERN IN THE "VIOLEIRO'S ORCHESTRA"}

\author{
Luiz Antonio Guerra \\ Universidade de Brasília \\ guerra.luizantonio@gmail.com
}

\section{Resumo}

Em meio ao recente movimento cultural da viola caipira, destacam-se as Orquestras de Violeiros. Desde a criação pioneira da Orquestra de Violeiros de Osasco, em 1967, dezenas de agrupações musicais semelhantes surgiram e se espalharam pela região centro-sul do Brasil. Trata-se de uma formação musical composta por vários violeiros, com repertório constituído majoritariamente pelo conhecido cancioneiro caipira. Participam das Orquestras instrumentistas de diferentes faixas etárias, escolaridade, sexo, formação musical, origens e contextos sociais, reunidos em torno da cultura e valores caipiras, com o objetivo de manutenção da tradição, aprendizado do instrumento e transmissão de técnicas de viola. As Orquestras têm sido guardiãs do repertório e da tradição da viola, contribuindo para a sobrevivência da música sertaneja raiz à margem da indústria fonográfica. Por outro lado, elas trazem consigo inovações na linguagem musical do repertório caipira, através de novos arranjos instrumentais orquestrados. Conclui-se que as Orquestras engendram uma forma muito particular de sociabilidade, onde se encontram a tradição e o moderno, o rural e o urbano. Constituemse, ao mesmo tempo, em espaços de renovação do instrumento e preservação da memória e valores da cultura rural. Representam, enfim, uma síntese das transformações recentes da viola caipira. Tendo em vista a enorme quantidade de violeiros que hoje participam das Orquestras, torna-se essencial um mapeamento e investigação aprofundada sobre esse fenômeno. Este trabalho apresenta um panorama dessas agrupações musicais no Brasil e reflexões que sirvam de base para uma pesquisa que vise à compreensão dos aspectos sociais e musicológicos das Orquestras.

Palavras-chave: Tradição; Viola Caipira; Orquestra de Violeiros. 


\section{Abstract}

In the middle of the recent cultural movement of the "viola caipira", the orchestras of Violeiros stand out. Since the pioneering creation of the Osasco's "Violeiros Orchestra" in 1967, dozens of similar musical ensembles have sprung up and spread throughout centralsouthern Brazil. It is a musical formation composed by several players of "viola caipira", with repertoire constituted mainly by the well-known country songbook. Participating in the orchestras instrumentalists of different ages, scholarity, gender, musical formation, origins and social contexts, gathered around the culture and values of the country, with the objective of maintaining tradition, learning the instrument and transmitting viola's techniques. The Orchestras have been guards of the repertoire and the tradition of the viola, contributing to the survival of the old music "sertaneja" in the margins of the music industry. On the other hand, they carry with them innovations in the musical language of the country repertoire, through new orchestrated instrumental arrangements. It is concluded that Orchestras engender a very particular form of sociability, where the tradition and the modern, the rural and the urban are found. They are, at the same time, spaces for the renewal of the instrument and preservation of the memory and values of rural culture. They represent, in short, a synthesis of the recent transformations of the "viola caipira". In view of the large number of "violeiros" who participate in the Orchestras today, an in-depth investigation and mapping of this phenomenon is essential. This work presents an overview of these musical groups in Brazil and reflections that serve as a basis for a research that aims at understanding the social and musicological aspects of Orchestras.

Keywords: Tradition; Viola Caipira; Violeiros Orchestra. 


\section{Introdução}

A viola, instrumento musical com forte identificação com a cultura do campo, nas últimas décadas, tem alcançado novos espaços socioculturais, articulando linguagens musicais diversas sem perder sua ligação elementar com as tradições da população camponesa do centro-sul do país, conhecida como caipira. Dentre esses espaços, destacam-se as Orquestras de Violeiros. Ao mesmo tempo em que promovem a sociabilidade em torno da tradição da música sertaneja, no seio das Orquestras florescem inovações técnicas e musicais que surgem a partir do encontro de novas linguagens com o antigo saber musical da viola caipira.

Neste trabalho, busco introduzir algumas reflexões sobre a tradição da viola caipira no mundo globalizado, a partir do recente fenômeno cultural das Orquestras de Violeiros. Inicio com uma breve história da viola, a formação da sua identidade caipira e suas transformações, até chegar na prática do instrumento nos dias de hoje. Apresento as Orquestras e o contexto no qual se inserem, lançando um olhar sobre o lugar e função da tradição da viola caipira nesses grupos. Defendo que tais agrupamentos musicais são espaços por excelência para pensar a tradição da viola caipira e justifico a necessidade de pesquisa aprofundada e mapeamento das Orquestras de Violeiros. Concluo a comunicação levantando algumas questões e temas de pesquisa suscitados pela prática musical e sociabilidade que ocorrem no interior desses grupos.

\section{Os caminhos da viola caipira}

Instrumento muito popular em Portugal na época em que os ibéricos, pela primeira vez, cruzaram o oceano Atlântico, a viola foi introduzida na Colônia especialmente pelas mãos dos jesuítas e passou a ser amplamente difundida pelos colonos no acompanhamento do canto e dança de diversos gêneros musicais e festas populares. Assim como no seu país de origem, a viola fazia parte da cultura urbana colonial, sendo popular principalmente nas primeiras capitais brasileiras!. Aos poucos, a viola e as manifestações culturais relacionadas a ela

I Sobre a viola no Brasil Colônia e Império, ver ABREU, 1999; ANDRADE, 1989; ARAÚJO, 1967; CANDIDO, 1956; CASTRO, 2005; CORRÊA, 2002; TINHORÃO, 1990; VILELA, 2013. 
foram sendo marginalizadas nas capitais e acabaram encontrando refúgio nas comunidades interioranas do país, onde foram recriadas e integradas às culturas rurais, a ponto de se tornarem indissociáveis. É nesse processo que a viola ganha o título pelo qual será mais conhecida e reconhecida: viola caipira.

A formação da cultura dos chamados caipiras, habitantes das zonas rurais do centro-sul do Brasil, está associada com os processos sócio-históricos de colonização das regiões sudeste e centro-oeste, ou seja, com as bandeiras que, a partir do século XVII, saíram de São Paulo com o objetivo de colonizar o interior do país e encontrar metais preciosos. Passada a corrida pelo ouro e prata, essa população mestiça se dispersou e sedentarizou, e os espaços por onde passaram as bandeiras foram ocupados por pequenos agricultores, que desenvolveram, com o passar dos séculos, determinados tipos de sociabilidade e cultura, expressos nos seus valores, costumes, crenças, culinária, técnicas de trabalho e cultivo, maneiras de falar a língua portuguesa, etc.

De acordo com Antonio Candido (1964), o principal locus do "modo caipira de existência" foram os bairros rurais, ou seja, pequenos núcleos habitacionais dispersos, originados do processo sócio-histórico das bandeiras, baseados em relações de parentesco e práticas de auxilio mútuo, onde se mantinha uma economia voltada à subsistência?

A viola tornou-se um elemento importante na sociabilidade dessa população camponesa, através de cantigas de roda, cantos de trabalho, rezas, danças e festas. José de Souza Martins afirma que a música no contexto dos antigos bairros rurais caracterizava-se "enquanto meio necessário para efetivação de certas relações sociais essenciais ao ciclo do cotidiano do caipira" (MARTINS, 1975, p. 112).

processo de concentração fundiária, urbanização e expansão da economia capitalista acarretou o desmantelamento da configuração sociocultural descrita por Candido. A partir do momento em que o habitante do campo se viu diante da necessidade de integrar-se à economia de mercado, a cultura caipira entrou em crise.

No mesmo período em que se iniciava a inexorável marcha migratória do campo para a cidade, foram gravadas as primeiras

2 Sobre os bairros rurais, ver também MARTINS, 1975 e QUEIROZ, 1967 e 1973. 
produções da música sertaneja, por iniciativa de Cornélio Pires, um dos responsáveis por consolidar a identidade da música caipira tal qual conhecemos hoje, com a formação de duplas de cantores tocando viola e violão. A partir da década de 1930, o rádio tornou-se o maior veículo de difusão da música caipira, alcançando inclusive as cidades interioranas e zonas rurais. A consolidação desse novo segmento musical afirmou, enfim, a viola como símbolo da cultura caipira.

Martins contrapõe aquela música caipira ligada exclusivamente à memória oral dos habitantes do campo, que existia apenas como "acompanhamento de algum ritual de religião, de trabalho ou de lazer" (Idem, p. 105), ao gênero sertanejo que surge com o advento do rádio e do disco, derivado daquela musicalidade rural, mas transformado em mercadoria para o consumo de massa e desprovido das suas antigas funções sociais.

O sociólogo Waldenyr Caldas considera a música sertaneja uma forma de alienação do camponês que migrou para a cidade, a partir do momento em que tal música é incorporada pela indústria cultural nascente. Utilizando-se das teorias da Escola de Frankfurt, Caldas estabelece a diferença entre a música caipira como manifestações culturais espontâneas e a música sertaneja que surgiu com a gravação de discos.

Se por um lado, a música sertaneja foi desprezada por Caldas, para quem, "do ponto de vista estético, (...) não se enquadra na categoria de arte (...) porque (...) é feita de redundâncias tanto ao nível da forma como do conteúdo" (CALDAS, 1979, p. 145-6), por outro lado, uma série de músicos e pesquisadores ${ }^{3}$ tem buscado demonstrar sua riqueza artística e importância social.

Ivan Vilela, violeiro, pesquisador e professor de música da USP, defende que as gravações das canções caipiras e sua radiodifusão provocou a popularização da viola e divulgou a voz dos camponeses do centro-oeste e sudeste. Nesse sentido, a música sertaneja teria sido essencial para a manutenção dos costumes e valores dessa população, permitindo que se estabelecesse na cidade sem perder totalmente a sua cultura de origem durante o processo de adaptação social chamado pelo autor de "desenraizamento". Para ele, a viola, como expressão

${ }^{3}$ Ver CORRÊA, 20 I4; NEPOMUCENO, 1999; SANT'ANNA, 2000; VILELA, 2013. 
por excelência da antiga cultura camponesa, serviu como instrumento de resistência cultural. Vilela conclui que foi justamente através das canções sertanejas que, mesmo "derrotados" e retirados da sua terra, a história dos habitantes do campo logrou ser contada - ou cantada, como diria o autor (VILELA, 2013).

O que conhecemos hoje por música caipira ou sertaneja raiz é aquela música do rádio das décadas de 1930 a 1960. Nesse periodo, a música e a viola caipira consolidaram sua identidade através de numerosas duplas, que incorporaram uma série de ritmos herdados pelos séculos de tradição oral da música rural no Brasil, tais como moda-de-viola, cururu, cateretê, toada, cana-verde, recortado, etc ${ }^{4}$.

Na década de 1940, a música caipira apropriou-se de ritmos paraguaios e argentinos, através das fronteiras do Mato Grosso e Paraná, que acabaram tornando-se característicos dos repertórios sertanejos, tais como a polca paraguaia, guarânia, chamamé e rasqueado. Já na década de 1950, o surgimento do "pagode de viola" - "síntese de dois ritmos caipiras, o cururu e o recortado" (Idem, p. 109) - constituiu em uma das principais inovações rítmicas da música rural. Essa inovação veio das mãos de grandes tocadores de viola, com destaque para Tião Carreiro, tido por muitos como o maior de todos os violeiros e inventor do pagode de viola. A ascensão do pagode marcou a era dos grandes instrumentistas e o ápice do desenvolvimento virtuoso da viola em sua identidade rural (Idem, p. 105).

A partir dos anos 1960, com a influência de gêneros como a jovem guarda, a balada romântica, a rancheira mexicana e o country norte-americano, o segmento musical sertanejo distanciou-se da estética das primeiras duplas caipiras e a viola foi sendo substituida pela guitarra elétrica, teclado e outros instrumentos eletrônicos. Cada vez menos jovens interessavam-se pela viola caipira, levando muitos violeiros a acreditar que o instrumento estava fadado ao desaparecimento. "Sua cultura [dos caipiras] foi tornando-se periférica, bem como todo o universo de valores que o cercava. Até a viola - acreditávamos nos anos de 1980 - começava a entrar em extinção por ser tratada como um instrumento menor", conta Ivan Vilela (Idem, p. 171).

\footnotetext{
4 "Desconhecemos na música popular algum segmento que abrigue tantos ritmos distintos. Afirmamos isso com base em nossas pesquisas. A música caipira é o maior guarda-chuva de ritmos distintos existente na música brasileira" (VILELA, 20|4. p. 7 I).
} 
Apesar de esquecida pela indústria fonográfica, a viola manteve-se presente nas festas religiosas e manifestações culturais nas zonas rurais, povoados, cidades do interior e periferias das metrópoles. Além disso, alguns programas de rádios locais continuaram tocando a música sertaneja raiz e certas duplas insistiram em manter a forma clássica de cantar duetado, resguardando a viola como o instrumento típico do cantar camponês.

Não obstante, Roberto Corrêa sugere que, a partir da década de 1960, alguns fatos anunciaram um movimento de nova expansão da viola caipira por todo o Brasil, chamado por Corrêa (2014 e 2015) de "avivamento da viola". Para ele, cinco acontecimentos são essenciais para compreender essa reviravolta na identidade da viola que ocorreria nas décadas posteriores: o próprio lançamento do pagode de viola por Tião Carreiro; as gravações dos primeiros discos de viola instrumental, por Julião e Zé do Rancho; a realização de escrita musical clássica para viola, pelo maestro Theodoro Nogueira; a conquista do 2० Festival de Música Popular Brasileira da TV Record em 1966, da canção "Disparada", de autoria Théo de Barros e Ceraldo Vandré, marcada pela temática rural e arranjo de viola caipira de Heraldo do Monte; e a criação da primeira Orquestra de Violeiros, em 1967, na cidade paulista de Osasco.

Se por um lado a viola caipira foi desprezada pela música sertaneja comercial que batia recordes de vendas no mercado fonográfico, por outro lado, nomes como Adauto Santos, Renato Teixeira, Almir Sater, Tavinho Moura e mesmo a dupla Pena Branca e Xavantinho, contribuíram para a renovação da sua identidade no âmbito da MPB, valorizando a raiz rural e popular do instrumento. Outros artistas passaram a se dedicar à viola instrumental, como Renato Andrade e sua "viola fantástica". Algumas iniciativas culturais também foram importantes para a manutenção da viola e cultura caipira, como certos programas televisivos que buscavam a autenticidade da cultura popular, destacando-se o "Viola Minha Viola”, apresentado por Inezita Barroso, e "Som Brasil", por Rolando Boldrin, também violeiros e entusiastas da tradição caipira.

Um fator que contribuiu para a retomada da prática da viola foi a criação dos primeiros cursos a partir da década de 1980. Até então, não havia escola de viola caipira e aquele que tivesse o interesse de tornar-se um violeiro deveria aprender sem a figura formal 
do professor, mas pela transmissão oral do saber musical por algum violeiro próximo ou por meio das práticas coletivas conhecidas como "rodas de viola"s.

pesquisador Saulo Dias (2010) mostra que no processo de escolarização da viola caipira não houve um rompimento com as práticas de ensino oral da viola, mas pelo contrário, a sistematização de técnicas de execução do instrumento deu-se com base no ensino informal realizado de maneira tradicional pelos tocadores de viola. Mesmo com a aparição de várias escolas e métodos impressos, proliferação de meios digitais de aprendizado e comunicação entre praticantes via internet, pode-se notar que a teoria musical está sendo mesclada com as técnicas tradicionais de execução da viola caipira. Para Dias, a vitalidade do ensino e prática da viola nos dias atuais está justamente na "resistência com os tocadores de tradições remanescentes, (...) que permite hoje aos novos violeiros dialogar de forma viva com o passado, ao invés de restringir-se a pesquisas em arquivos ou em gravações fonográficas" (DIAS, 2010, p. 208).

Concomitantemente à escolarização da viola - e intimamente ligados a esse processo - "novos violeiros" despontaram - e despontam - no cenário musical, de maneira paralela e independente ao mercado sertanejo dominante, seja em carreira solo, duplas ou como parte de bandas musicais. Além de instrumentistas, muitos desses novos violeiros são também pesquisadores das tradições rurais populares das quais são herdeiros. A crescente produção musical é protagonizada por violeiros e grupos que exploram ilimitadas possibilidades de criação da viola, tendo, porém, a cultura caipira como referência estética obrigatória. De acordo com José Roberto Zan, novas gerações de violeiros têm voltado suas atenções para as "manifestações musicais tradicionais" e produzido "repertórios híbridos" em que se misturam a música caipira com elementos modernos da cultura urbana, popular e erudita (ZAN, 2008).

Os novos violeiros trazem para as suas composições suas memórias - individuais e coletivas - vinculadas à ruralidade e à música

\footnotetext{
5 "A roda de viola consiste numa prática musical coletiva entre os violeiros da tradição oral, conservando um traço característico da viola caipira. Na roda, toca-se em torno do instrumento e se canta o repertório típico da música sertaneja raiz. Nessa ocasião, os violeiros têm a oportunidade de se observarem para depois tentarem refazer o que ficou gravado naquela experiência" (DIAS, 2010, p. 18).
} 
caipira, folguedos e festas populares, tais como congadas, folias e festas de São Conçalo, santo padroeiro dos violeiros. Também são recorrentes as alusões ao folclore em torno da viola, mitos e superstições que ainda hoje persistem entre os violeiros, como a ideia do dom divino e histórias de pactos com o diabo para se tornar um grande tocador.

Na música feita hoje com a viola caipira são bem marcados vários recursos técnicos peculiares e a sonoridade característica do instrumento. A viola caipira apresenta "sons rústicos, raspados, estridentes, grosseiros, imperfeitos", que, de acordo com Ivan Vilela, "fogem ao padrão estético" da música e instrumentos modernos, mas que se trata de "timbres e texturas que as músicas clássica e popular são, na maioria das vezes, incapazes de produzir" (VILELA, 2013, p. 73). A viola caipira formou uma linguagem musical própria, com técnicas de execução como "ponteado, paralelismo, rasgueado, arraste" (DIAS, 2010 , p.17) transmitidas de geração em geração, que servem para caracterizar o timbre da viola e acentuar o universo caipira em que ela está inserida.

É interessante observar que nas mãos dos atuais violeiros ou nos métodos de ensino hodiernos esses recursos técnicos tradicionais não são eliminados e esquecidos, mas pelo contrário, são valorizados pelos tocadores e sistematizados pelos professores como parte essencial do saber musical da viola. Não seriam justamente suas tradições rurais, sua sonoridade peculiar e esse "encantamento" que permanece vivo e reproduzido na viola, o que atrai hoje tanto os já consagrados violeiros quanto os jovens aprendizes?

\section{As Orquestras de Violeiros}

A organização de tocadores de viola em formação de orquestra é um fenômeno cultural recente. A criação pioneira da Orquestra de Violeiros de Osasco (SP), pelo maestro Marino Cafundó no ano de 1967, é considerada um marco no "avivamento" da viola (CORRÊA, 2014), mas é a partir da década de 1990 que se observa uma multiplicação desses agrupamentos musicais.

- primeiro levantamento sobre o número e distribuição geográfica das Orquestras de Violeiros existentes foi realizado por Saulo Dias (2010), quando foram catalogadas 94 (noventa e quatro) 
Orquestras distribuídas em 05 (cinco) estados, sendo a maioria (67) em São Paulo. Três anos depois, uma nova pesquisa (PEDRO, 2013) encontrou 122 (cento e vinte e dois) grupos em 09 (nove) unidades federativas da região centro-sul do Brasil.

De acordo com ambos os pesquisadores, a disseminação das Orquestras está associada ao crescente processo de escolarização da viola, já que grande parte dos grupos foram criados por professores a partir das práticas de ensino do instrumento. Muitas delas são mantidas por fundações culturais, associações e ONGs; outras por prefeituras e secretarias de fomento à cultura, educação e ação social; há ainda grupos privados que dependem da contribuição financeira dos próprios membros, venda de materiais e apresentações. As Orquestras apresentam-se usualmente em eventos em praça pública, feiras agropecuárias, festivais de música e cultura popular, festas juninas, festividades religiosas, escolas e universidades, encontros promovidos entre as próprias Orquestras, programas de rádio e televisão, etc. Os membros das Orquestras, em geral, organizam-se por meio de meios digitais e redes sociais, além de utilizarem massivamente a internet para divulgar materiais audiovisuais e promover o grupo, compartilhar recursos virtuais de ensino do instrumento e conteúdo relacionado com a cultura caipira.

Tais agrupamentos musicais caracterizam-se, sobretudo, por serem compostos por vários violeiros, dirigidos por um regente, também violeiro. Algumas Orquestras são formadas apenas por violas, mas é comum também encontrarmos grupos com cantores (solo, em dupla ou coral) e instrumentos variados, como violão, contrabaixo, percussão, acordeon, flauta, entre outros. Um segundo elemento que define as Orquestras de Violeiros é o seu repertório baseado nas canções clássicas da música sertaneja raiz. Tem-se, assim, a tradição da música caipira como a essência estética das Orquestras de Violeiros.

Essas Orquestras congregam pessoas de diferentes perfis socioeconômicos, trajetórias de vida distintas, variadas faixas etárias, gênero, escolaridade e formação cultural, com o objetivo comum da prática coletiva de viola caipira. Por congregar vários violeiros, antes dispersos, em um local de sociabilidade e troca de saberes, as Orquestras assemelham-se às tradicionais rodas de viola, onde vários violeiros tocam juntos, em formação circular, canções conhecidas do repertório sertanejo, alternando entre si a execução de acompanhamento e solos, 
de forma a intercambiar entre os membros técnicas do instrumento e conhecimentos sobre a música caipira. Ao mesmo tempo em que mantêm a tradição do instrumento, as Orquestras promovem inovações técnicas e musicais, a partir da composição de novos arranjos instrumentais para as clássicas canções caipiras, dialogando outras linguagens com antigo saber musical da viola.

Enquanto os meios de comunicação em massa abandonavam a música e a viola caipira, as Orquestras, de maneira independente, cumpriam o papel de passar oralmente o repertório sertanejo raiz, técnicas de viola e celebrar a cultura caipira. Pode-se dizer, portanto, que desde o aparecimento das primeiras Orquestras, elas se consolidaram como "guardiãs da viola", no sentido de resguardar e manter a tradição do instrumento. Além de grupos musicais, as Orquestras têm funções sociais valiosas de formar novos violeiros, fomentar a música popular e a prática da viola, ser um espaço de interação sociocultural, encontro entre antigos e novos instrumentistas, troca de saberes, preservação da memória e da cultura caipira e, sobretudo, de reconhecimento e sociabilidade entre os sujeitos.

\section{Considerações finais: Pesquisando as Orquestras de Violeiros}

Assistimos a um intenso movimento cultural em torno da viola caipira que cada vez mais tem chamado a atenção da comunidade acadêmica, nas áreas de ciências sociais, comunicação e artes, além de agentes governamentais, produtores culturais e público consumidor de cultura.

Entretanto, escassos trabalhos acadêmicos sobre a viola caipira abordam as Orquestras de Violeiros, sendo que existem apenas dois estudos que tratam mais diretamente esses agrupamentos musicais. $\bigcirc$ primeiro é a tese de doutorado de Saulo Sandro Alves Dias, defendida em 2010, na Faculdade de Educação da Universidade de São Paulo (USP), com o título de "O processo de escolarização da viola caipira: novos violeiros (in) ventano modas e identidades". O objeto da tese é a escolarização da viola; porém, por considerá-las uma importante forma de escolarização não-formal, o autor dedica uma parte do primeiro 
capítulo ao caso das Orquestras de Violeiros ${ }^{6}$. A tese de Dias tornou-se referencia no tema por ter sido a primeira vez em que as Orquestras foram de fato mapeadas e pensadas teoricamente.

único trabalho acadêmico que tem uma Orquestra de Violeiros como objeto de pesquisa central é a dissertação de mestrado em música da Universidade Estadual de Campinas (UNICAMP), de Renato Cardinali Pedro, intitulada "Uma Orquestra de viola caipira no município de São Carlos", defendida em 2013. Trata-se de um estudo de caso, no âmbito da etnomusicologia, de uma única Orquestra ("Orquestra Amigos Violeiros de São Carlos").

Tais estudos abriram caminhos para inúmeras reflexões teóricas suscitadas pela disseminação das Orquestras de Violeiros. $\bigcirc$ tema pede uma investigação aprofundada, como meio para a compreensão dos aspectos sociais da viola caipira hoje. Faz-se necessário também a atualização e verificação dos dados levantados por Dias e Pedro, através de um mapeamento rigoroso das Orquestras de Violeiros, sua distribuição geográfica pelo Brasil e o número estimado de violeiros que participam desses grupos.

Acredito que as Orquestras de Violeiros são espaços privilegiados para pensar as tradições e identidades relacionadas à cultura caipira na região centro-sul do Brasil, por se tratar de um fenômeno cultural recente de expressão da viola que enseja uma sociabilidade entre pessoas de diferentes perfis socioculturais em torno de certos valores que envolvem o instrumento. Nessas Orquestras, discursos de ruralidade são constantemente mobilizados em meio a um processo de reafirmação e, ao mesmo tempo, ressignificação da identidade da viola caipira.

principal objetivo da pesquisa que venho realizando é compreender o lugar e o papel das tradições nas transformações da identidade da viola caipira e de seus tocadores que ocorrem a partir da prática musical e sociabilidade promovidas pelas Orquestras de Violeiros. Da perspectiva da sociologia da cultura, busco investigar os discursos sobre a tradição em torno da viola no contexto atual de globalização.

"Itens "1.2.1.2 - O ensino não-formal: o caso das orquestras de viola" e "1.2.1.3 - Quadro da distribuição geográfica das orquestras de viola", do capítulo primeiro, intitulado "A tradição e escolarização da viola caipira" em DIAS, 2010 , páginas 48 a 56. 
A breve apresentação da viola caipira e das Orquestras de Violeiros realizada neste trabalho nos fornece alguns elementos essenciais para pensar a tradição da viola e da cultura caipira na contemporaneidade e levanta uma série de questões a serem investigadas, com as quais concluo a presente comunicação.

Como as Orquestras têm reafirmado e transformado a identidade da viola, do violeiro, da música e cultura caipira? Qual a função das tradições na prática musical e sociabilidade que se dão no âmbito das Orquestras de Violeiros? Como os membros das Orquestras enxergam a prática da viola caipira na atualidade? $\bigcirc$ que entendem ser a tradição do instrumento e qual a relação com suas memórias? Quais as consequências do encontro de novos e antigos violeiros? $\bigcirc$ que levaram os membros das Orquestras a se dedicarem à viola? $\bigcirc$ que os motivam a participar das Orquestras? Qual a quantidade de Orquestras existentes e violeiros envolvidos? Quais os fatores sociais, culturais, econômicos e políticos que levaram à expansão das Orquestras de Violeiros e os agentes que influem na criação, manutenção e exitos desses agrupamentos musicais? Como se dá o uso de novas tecnologias e mídias digitais como estratégia de comunicação e sua relação com a tradição oral da viola caipira?

\section{Referências bibliográficas}

ABREU, Martha. O império do divino. Rio de Janeiro, Nova Fronteira, 1999.

ANDRADE, Mário de. Dicionário musical brasileiro. Belo Horizonte: Itatiaia / [Brasília]: Ministério da Cultura / São Paulo: Instituto de Estudos Brasileiros da Universidade de, 1989.

ARAÚJO, Alceu Maynard de. Viola. Folclore Nacional, Vol. II, p. 433-45I, 2 ed. São Paulo: Melhoramentos, 1967.

CALDAS, Waldenyr. Acorde na Aurora: música sertaneja e indústria cultural. 2 ed. São Paulo: Ed. Nacional, 1979. 
CANDIDO, Antonio. Possíveis raízes indigenas de uma dança popular. Revista de Antropologia, v. IV, n. I, p. 1-24, São Paulo: junho de 1956.

José Olympio, 1964.

Os parceiros do rio bonito. Rio de Janeiro: Livraria

CASTRO, Renato Moreira Varoni de. $\bigcirc$ violão substitui a viola de arame na cidade do Rio de Janeiro no século XIX. In: XV Congresso da ANPPOM, Rio de Janeiro, 2005.

CORRÊA, Roberto Nunes. Viola caipira: das práticas populares à escritura da arte. São Paulo, 2014. Tese (Doutorado em Música) Universidade de São Paulo.

Violas brasileiras: circuito 2015/20/6. Rio de Janeiro: SESC, Departamento Nacional, 2015.

DIAS, Saulo Sandro Alves. O processo de escolarização da viola caipira: novos violeiros (in)ventano moda e identidades. São Paulo, 20 10. Tese (Doutorado em Educação) - Universidade de São Paulo.

MARTINS, José de Souza. Música Sertaneja: A dissimulação na linguagem dos humilhados. In: Capitalismo e tradicionalismo. São Paulo: Pioneira, 1975.

NEPOMUCENO, Rosa. Música caipira: da roça ao rodeio. São Paulo: Ed. 34, 1999.

PEDRO, Renato Cardinali. Uma Orquestra de Viola Caipira do município de São Carlos. Campinas, 20 13. Dissertação (Mestrado em Música) Universidade Estadual de Campinas.

QUEIROZ, Maria Isaura Pereira. Bairros rurais paulista. Revista do Museu Paulista, n. 17, p. 63-210, São Paulo, 1967.

O campesinato brasileiro. Petrópolis: Ed. Vozes, 1973.

SANT'ANNA, Romildo. A moda é viola: ensaio do cantar caipira. Marilia: Ed. Unimar, 2000. 
SOUZA, Andréa Carneiro de. Viola - do sertão para as salas de concerto: a visão de quatro violeiros. Rio de Janeiro, 2002. Dissertação (Mestrado em Música) - Universidade do Rio de Janeiro.

TINHORÃO, José Ramos. Historia social da música popular brasileira. Lisboa: Editorial Caminho, 1990.

VILELA, Ivan. Cantando a própria história: música caipira e enraizamento. São Paulo: Editora da Universidade de São Paulo, 2013.

ZAN, José Roberto. Tradição e assimilação na música sertaneja. In: XI Congresso Internacional de Brazilian Studies Association (BRASA), Lovisiana, 2008.

\section{Sobre o autor}

Luiz Antonio Guerra é doutorando em Sociologia na Universidade de São Paulo (USP), mestre em Sociologia e bacharel em Ciência Política pela Universidade de Brasília (UnB). O autor também é violeiro e realiza pesquisas sobre viola e cultura caipira.

Recebido em: 10/09/2016 Aprovado em: 09/1 1/2016 